\title{
'An exploration of stakeholder involvement in decision-making: a qualitative study of commissioning for alcohol services'
}

hayley Alderson ( $\sim$ hayley.alderson@newcastle.ac.uk)

Newcastle University https://orcid.org/0000-0002-4674-561X

Eileen Kaner

Newcastle University Institute for Health and Society

David Hunter

Newcastle University

Amy O'Donnell

Newcastle University

Angela Bate

Northumbria University

Research article

Keywords: Stakeholder involvement, Commissioning, Alcohol

Posted Date: April 27th, 2020

DOI: https://doi.org/10.21203/rs.3.rs-24294/v1

License: (c) (i) This work is licensed under a Creative Commons Attribution 4.0 International License. Read Full License 


\section{Abstract}

Background: The concept of providing individuals with a 'voice' via stakeholder involvement has been advocated within English health care policy for several decades. Stakeholder involvement encourages people affected by an issue to contribute to planning and decision making regarding treatment and care, inclusive of providers and recipients of care. This paper explores stakeholder involvement within the commissioning of public health alcohol services and illustrates whether stakeholders perceived that meaningful involvement had taken place.

Methods: We conducted a qualitative case study, inclusive of in-depth interviews with 10 Alcohol commissioners, 11 alcohol service providers and 6 general practitioners plus three facilitated focus groups with 31 alcohol service users. All interviews and focus groups were audio-recorded and data were transcribed verbatim. Thematic analysis drawing on Arnstein's theory was used to discuss key issues related to participants involvement which are illuminated using direct quotes.

Results: Overall findings suggest that most participants were aware of and could name various methods of stakeholder involvement, methods varied from formal strategically imposed mechanisms to innovative opportunities. We found that strategic mechanisms of involvement focused on collating data to help construct a national picture regarding service delivery. Using Arnstein's ladder to illustrate the extent of stakeholder involvement, the majority of the participants perceived involvement to occur at the level of informing or consultation implying a level of tokenism. In addition, the impact of stakeholder involvement is not systematically monitored making it hard to identify the impact that involvement methods have had.

Conclusion: This paper has shown a lack of consistency regarding the opportunities within the commissioning process for stakeholder involvement to influence service design and delivery. It is essential within public health that a deeper understanding is generated of who stakeholders are within this complex and fluid environment and to develop a clearer understanding of the different roles that stakeholders can play within the entire commissioning process in order to maximise its utility. Future commissioning guidance also needs to reflect more dimensionality than ladders of involvement currently afford.

\section{Background (5636-word Count)}

Commissioning has been described as a cyclical and iterative process that ensures the needs of the population are effectively met through the provision of social care services (1-3). Commissioning involves assessing the needs of a population, responding to the highlighted needs, and designing and implementing care pathways around those needs (4). In an attempt to become more responsive to the needs of the population, the concept of providing individuals with a 'voice' via stakeholder involvement has been advocated within English health care policy for several decades (5-7). The need for patient involvement was flagged in the 1982 Working for Patients white paper (8). However, moves to increase stakeholder involvement in care decision-making have accelerated in recent years in response to two 
major factors, one being that politicians demand greater efficiency from services and an effective use of public funds; and, secondly, due to members of the public demanding increased involvement in decisions about their care and services $(9,10)$.

The 2007 world class commissioning (WCC) framework (11) was one of the first policies that explicitly charged commissioners within the English National Health Service (NHS) with the task of pursuing ongoing and meaningful involvement with stakeholders (12). The WCC framework was superseded by the Health and Social Care Act 2012 which required Clinical Commissioning Groups (groups of general practices) in England to work together to plan, design and manage health services within their local areas. Clinical commissioning groups were also tasked with enabling patients and members of the public to participate in the process of commissioning (6).

More recently, Transforming Participation in Health and Care (6), the NHS England guidance Patient and Public participation: in commissioning health and care, and the 2019 NHS Long Term Plan (13) have set out key actions on how to embed the involvement of members of the public and stakeholders in their work (7). Indeed, the NHS Long Term Plan (13), alongside the Think Local act Personal partnership, shows the support which exists for greater personalisation of health and social care (14) where citizens and patients have a greater role in policy-making and shared decision-making in health and care settings (15).

There are several perceived benefits of involving stakeholders in commissioning. Stakeholder involvement has the potential to present everyone involved in commissioning and decision-making to different perceptions and standpoints which facilitate a broader understanding to be obtained regarding the community context that exists (16-18). Additionally, it may strengthen democracy and enhance the credibility of services by promoting an understanding of the issues, reducing uncertainty and promoting trust and legitimacy on behalf of service users $(4,19)$ which in turn could improve the sustainability of public health services if stakeholders have confidence that services are endeavouring to meet their needs (20-22).

Elliott and Williams (23) have argued that the experiential wisdom that lay people hold is a form of legitimate expertise which can become 'the basis for a powerful form of knowledge production' adding an extra dimension within the commissioning process (4). A lay person is a person who is not trained, qualified or experienced in a particular subject or activity (24).

Despite the perceived benefits of stakeholder involvement, the process of involving stakeholders in the commissioning process can be complicated as any individual can be considered a stakeholder if they are affected by or can affect an issue (i.e. alcohol) (25). Furthermore, the identity of individual stakeholders is not fixed, the level of interest an individual has regarding an issue and the ability to influence may fluctuate. An array of terms such as patient, client, service user and customer are interchangeably used in health and social care contexts (4). The multifaceted nature of alcohol use and misuse lends itself to individuals encompassing multiple identities where needs are managed across statutory and voluntary services covering both health and social needs. The varied collection of terms serves to emphasise how it 
is possible for confusion to arise when trying to establish who stakeholders are regarding alcohol use/misuse and alcohol service provision.

When considering alcohol service users specifically as potential stakeholders in commissioning, the extent of alcohol use/misuse is varied. It is estimated that 10.4 million adults consume alcohol at levels that increase their potential for health related harms (26), many individuals who fall within this category would not consider themselves to have a problem and would not contemplate attending specialist services (4). An estimated 595,000 adults may need treatment for alcohol dependence although Rehm and Roerecke have identified that the majority of alcohol related mortality and morbidity is as a result of heavy (though not necessarily dependent) alcohol consumption (27). This highlights a challenge for commissioners when considering intervention options across the entire prevention, treatment and recovery continuum.

Types of stakeholder involvement can vary significantly from a one off consultation to engaging in continual exchanges of ideas and negotiation regarding the planning, design and management of services (28). Arnstein's (1969) ladder of participation (29) represents one version of how stakeholder involvement can be interpreted (Fig. 1). Commentators such as Feingold (30) Burns et al (31) and Wilcox (32) have redesigned Arnstein's model to fit their respective contexts that they are working in. Different commentators acknowledged that different levels of involvement are appropriate at different times to meet the expectations of different stakeholders involved in the process (33).

Arnstein's ladder is used within this paper, it illustrates eight potential ways that stakeholders and community members can participate in decision making. Arnstein argued that only the top three rungs of the ladder - partnership, delegated power and citizen control - represent genuine participation with people, with the five rungs below symbolising tokenism (4). Tokenism is understood to mean the process of only making a symbolic effort to do a particular thing, such as only targeting a small number of individuals within a 'hard to reach', vulnerable or excluded group, in order to give the appearance of equality (34). The ladder emphasises that there is a substantial distinction between an individual having the required level of power and influence to affect an outcome within a decision making process and the symbolic ritual of participation (29). This study did not aim to refute Arnstein's model or propose it as an ideal model to be adopted within alcohol commissioning, it was used to contextualise the different levels of involvement described as taking place within the commissioning process.

However, despite increased attention in recent decades, a number of commentators have identified that, within many public health and clinical settings, stakeholder involvement remains rhetorical and could be considered to be tokenistic, according to Arnstein's ladder as described above (35-37). A number of studies report inconsistencies between the stated levels of stakeholder involvement that occur and the actual extent of involvement taking place in the multiple stages of the commissioning process (37-41).

In the context of the study reported in this paper, the term stakeholder involvement was used to denote participation or engagement at any level in the design, development and delivery of services. This paper uses the example of alcohol services to explore the experiences and perceptions of stakeholder 
involvement in the planning and commissioning of publicly funded services offering treatment and care to adults in need of support for alcohol related problems.

\section{Methods}

The research took place between 2009 and 2016 as part of a PhD thesis. The PhD was funded by an NHS organisation within the North East of England, the NHS organisation encompassed three different local authority areas with a combined population of 629,204 people (42). The remit of the $\mathrm{PhD}$ enquiry was to explore the commissioning process. Therefore a case study design was adopted to explore stakeholder knowledge/awareness of the commissioning process and experiences of being involved in alcohol service commissioning within the boundaries of a specific environment or organisation $(43,44)$ in this case three local authority areas in the North East Region. At the time of the study, Primary Care Trusts (PCTs) were part of the NHS. They functioned between 2001 and 2013 and were responsible for commissioning primary, secondary and community health services from providers. PCTs were abolished in 2013 and CCGs took over their commissioning responsibilities.

Qualitative semi-structured interviews and/or focus group interviews were used to gain multiple perspectives from participants on whether stakeholders felt they had opportunities to be involved in decisions being made about alcohol treatment service provision. Two data collection methods were used. Semi-structured interviews were used with professional stakeholders, they provided enough flexibility to engage participants within busy work schedules and enable a wealth of information to be sought from participants. Focus groups were used with service users as they helped to stimulate discussions between group members and facilitate a range of responses to be sought in a relatively short space of time (45). We used focus groups as it was felt that the group environment may provide service users with 'reassurance', it enabled data to be sought without participants feeling pressurised to answer every question (46). It was also hoped that focus groups would lessen any potential power differentials between the researcher and the participants. Semi-structured topic guide were used in interviews and focus groups (47) to explore; stakeholders awareness of opportunities that were available for them to be involved in commissioning, which mechanisms of involvement stakeholders had taken part in, the perceived barriers and facilitators of involvement mechanisms used and how much influence stakeholders felt that had regarding decisions made.

Purposive sampling was employed with professional participants (Alcohol commissioners and adult drug and alcohol services within the three PCT case study sites). The NHS organisation funding the study provided a list of all members of the alcohol commissioning team and all available adult drug and alcohol services within the case study sites, therefore the population groups were pre-defined. Professional participants were recruited to ensure maximum diversity across the three PCT case study sites. Snowball sampling was used to recruit general practitioners (GPs). A single name of a GP with special interest in alcohol was provided by the NHS organisation, this GP then identified further colleagues with an interest in alcohol and/or commissioning who may be willing to participate in the study. 
Finally typical case sampling (48) was used to recruit service users. The typical case within this study was defined as an individual in receipt of support via a specialist drug and alcohol service regarding their alcohol intake. Service users were invited to participate regardless of the tier of service (prevention, cure or treatment) they accessed (4). Additional inclusion criterion for service users were that the participant was 18 years old or over, alcohol was their primary substance misuse problem, and they could provide informed consent. Recruitment continued until data saturation was reached and no new themes arose from the data (49). All professional participants were contacted directly by the researcher via telephone. Service user participants were approached in person (face to face) by the service user involvement officer working across the three PCT sites.

Once participants had provided verbal consent to take part in the research, an appropriate time, date and location were agreed to conduct the interview. Focus group discussions took place within active alcohol services, a service user involvement officer helped to recruit participants. Service users received a $£ 10$ voucher as remuneration for their time. Written consent was obtained from all participants prior to taking part in the study.

\section{Analysis}

All interviews were audio recorded, transcribed verbatim and subject to in-depth, thematic analysis (50). An iterative process, using the constant comparison method (51), was adopted in order to identify key themes and concepts emerging from the data. Qualitative software (NVIVO) aided the organisation of thematic codes. The main themes and findings were discussed and reflected on with the co-authors whose expertise included public health, commissioning and drug and alcohol use. The results of the analysis are presented below using verbatim quotes to illustrate the findings. Arnstein's model of citizen engagement (29) has been used to help to visually depict the ways in which people have been involved in alcohol decision-making.

\section{Results}

The findings reported here are derived from an analysis of data obtained from 58 stakeholders, as shown in Table 1. The qualitative quotes used to illustrate the themes within this paper are part of a wider dataset completed as part of my PhD thesis (4). 
Table 1

Study participants

\begin{tabular}{|llllll|}
\hline $\begin{array}{l}\text { Participant } \\
\text { group }\end{array}$ & Demographics & $\begin{array}{l}\text { PCT } \\
\mathbf{1}\end{array}$ & $\begin{array}{l}\text { PCT } \\
\mathbf{2}\end{array}$ & $\begin{array}{l}\text { PCT } \\
\mathbf{3}\end{array}$ & Total \\
\hline $\begin{array}{l}\text { Alcohol service } \\
\text { users }\end{array}$ & $\begin{array}{l}\text { Male }(\mathrm{n}=18) ; \\
\text { Female }(\mathrm{n}= \\
\text { 13) }\end{array}$ & 11 & 12 & 8 & 31 \\
\hline $\begin{array}{l}\text { Service } \\
\text { providers }\end{array}$ & $\begin{array}{l}\text { Male }(\mathrm{n}=4) ; \\
\text { Female }(\mathrm{n}=7)\end{array}$ & 2 & 2 & 2 & $\begin{array}{l}10 \text { (4 providers offered services across all } \\
3 \text { areas- the strategic manager was } \\
\text { interviewed })\end{array}$ \\
\hline $\begin{array}{l}\text { Alcohol } \\
\text { commissioners }\end{array}$ & $\begin{array}{l}\text { Male }(\mathrm{n}=6) ; \\
\text { Female }(\mathrm{n}=4)\end{array}$ & 4 & 3 & 2 & $\begin{array}{l}11(2 \text { commissioners worked strategically } \\
\text { across all 3 areas })\end{array}$ \\
\hline $\begin{array}{l}\text { General } \\
\text { Practitioners }\end{array}$ & $\begin{array}{l}\text { Male }(\mathrm{n}=5) ; \\
\text { Female }(\mathrm{n}=1)\end{array}$ & 2 & 2 & 2 & 6 \\
\hline
\end{tabular}

Within the interviews and focus groups, all participants described opportunities for stakeholder involvement in terms of the mechanisms and approaches they encountered. Examples of stakeholder involvement varied from the formal strategically imposed mechanisms such as annual satisfaction questionnaires, to innovative opportunities for open-ended stakeholder involvement to occur. The analysis and discussion of participants' reflections are explored in further depth below.

\section{Involvement mechanisms denoting tokenism}

Formal methods of stakeholder involvement were expressed by participants as events taking place at a scheduled time such as a specific point in a treatment process i.e. an individual's entry into or exit from an episode of care. Prescribed methods of stakeholder involvement were predominantly imposed externally and included annual satisfaction surveys and questionnaires, and strategic groups and meetings.

\section{Annual satisfaction surveys and questionnaires}

Alcohol service managers presented examples of methods of stakeholder involvement that they carried out to satisfy external requirements. Such mechanisms consisted of completing documents such as a generic service evaluation forms or annual satisfaction surveys with pre-determined questions that were regulated at a national level and were issued to all alcohol service providers. These standardised documents aimed to collate information for statistical purposes rather than to assemble information that reflected an individual's journey and the associated experiences of treatment provision. Each alcohol service gathered information to help construct a national picture of the service users' opinion regarding the treatment provision they have received. For some service managers, the purpose of using these 
standardised involvement mechanisms was to performance monitor their organisation, as the quote below implies:

"It's done as part of the larger organisation and they will do a six-monthly service users surveys which is fed back up the chain if you like, so you know, so that they know we're doing our jobs properly here." (Kat, Service Provider)

This mechanism of involvement served a purpose to feed information along the chain of command to commissioners regarding an individual's 'satisfaction' regarding services. These mechanisms were portrayed as having limited scope for stakeholders to influence the design or delivery of services. Additionally, these mechanisms only permit a snapshot of feedback to be acquired and they promote a one-way flow of information. It was not clear whether the information collected was made available or fed back to providers and service users and consequently the impact of this form of stakeholder involvement was uncertain.

Regardless of the unquantifiable scope of questionnaires and surveys, commissioning participants described them as suitable mechanisms to collect stakeholder views regarding service provision as emphasised by Laura: "We have a really good service user network in terms of we do a lot of questionnaires and I know people get sick of them but it's about constant improvement and looking for different ways coz if it's not working they are the people that are gonna know about it." (Laura, Commissioner)

In contrast, service users questioned whether surveys and questionnaires as methods of involvement were 'fit for purpose'. Most of the service users identified that they had completed a questionnaire and/or survey whilst accessing alcohol treatment services. In contract to the quote by Laura above, all service user participants felt that questionnaires were the wrong mechanism to collect quality and insightful views regarding services. The structure of these mechanisms of involvement were deemed to be too formal and they did not provide adequate opportunities for service users to express themselves. One participant explained that: "A questionnaire can't get across the feelings and experiences, you can tick boxes but really, it's not gonna give any more than that" (Oscar, Service user).

Moreover, service user participants perceived that questionnaires did not reflect a genuine interest in fully understanding individuals, views: "The questionnaires, the questions that they ask ya and the boxes you've gotta tick, you probably tick the boxes but it's not your true feelings, ya cannat express yourself in a ticky box situation, its limited to what they want to know not what ye think ya want them to kna." (Tony, Service user). Service user participants articulated that a crucial component of any stakeholder involvement experience, was to feel as though their opinions and lived experiences had been heard. Service users suggested that this was the main aspect currently missing from current methods of stakeholder involvement and this led to frustration regarding the limited scope of involvement mechanisms to capture contextual and personalised information. Participants suggested face to face meetings would be more appropriate: "You don't see the people behind the names, you just look at a load of questionnaires filled in by a load of people and there is still stigma attached to that. Whereas if you 
come here and you see the people face to face and you see that they're just human beings like everybody else, you know. I think it kind of; it adds a lot more sort of strength to it than just words on a bit of paper." (Emily, Service User)

\section{Strategic groups and meetings}

Service provider participants explained that they felt that contract review meeting that took place monthly between themselves and commissioners were one of the main opportunities for them to liaise with commissioners. It was uncertain how this mechanism of involvement influenced the commissioning process. "Every three months they'll have a site visit where they'll literally come in and walk around and look for evidence of what we've said we produce" (Donna, Service Provider). Service providers perceived that structured methods of consultation were used to monitor their performance. From this perspective, there was limited possibilities for genuine consultation to take place, with few opportunities for discussion to occur regarding how a service may evolve. Conversely, commissioning participants reported that mechanism were available for professional stakeholders to be involved in the commissioning processes: "We have a joint commissioning group where all partners sit around, so they would be involved in any commissioning arrangements" (Beth, Commissioner).

General practitioners also discussed their involvement in strategic meetings. From their perspective they described feeling as though they had been 'consulted': "I feel I've been consulted appropriately. I think that [you know] the PCT does have a desire to consult and listen - genuinely. What I can't influence is their ultimate decisions say on financial matters; and that's fair enough, that shouldn't be my decision" (George, General Practitioner).

From a different perspective, one GP felt that their voice had the potential to be excluded due to their dual role as both a clinician and a stakeholder; "My Clinical Lead voice has been excluded but then I mean I understood you know why there had to be this you know because I am a provider as well you know that they, I couldn't have a commissioning role" (Greg, General Practitioner).

Predominantly methods of involvement were described as occurring at the level of consultation. Genuinely inclusive methods of involvement were noticeable in one location (service B) where service users explained that service managers held formal committee meetings that were open for services users to attend: "I would say, given the fact that this is, it's like the meeting every 2 months with the powers that be (service managers) and that's another level of getting things passed on to management or whatever, coz what it is basically is that they sit and listen to everybody." (Sarah, Service User). These open meetings provided an environment where service users and individuals volunteering within the service could communicate their views on a regular and ongoing basis.

\section{Involvement mechanisms with potential for innovation}

Despite the involvement mechanisms denoting tokenism being the most prevalent, participants also describe opportunities for more 'authentic' stakeholder involvement to occur on a more informal and sometimes spontaneous basis. When discussing the informal mechanisms, participants described them 
as being responsive and needs led rather than imposed at pre-specified times. Informal processes included direct consultation and user-led innovation.

\section{Direct consultation}

Service providers identified innovative methods of engagement at a local service provider level with Kat stating that: "I think it's very important to listen to the client, you know they've got the answers so we've just introduced part of our new recruitment strategy is we have a client or couple of clients showing the candidates round giving you know the tour of the place and informing them how things run in here and then we sit at the end of the interviews with the clients and take feed-back from them and what they thought about the candidates." (Kat, Service Provider).

The majority of services providers identified that stakeholder involvement took place within their individual organisations. At this local level involvement opportunities were described as continuously available. At a localised level, experiences of service provision were gathered using multiple methods such as service user feedback forms, suggestion boxes, evaluation sheets and patient stories. Services portrayed a commitment to providing several methods for individuals to communicate their experiences; "there's various ways and methods that people can communicate which will make them feel most comfortable" (Donna, Service Provider). The availability of different methods of involvement indicated a deliberate attempt to offer service users a format that was appropriate for everyone. For example, service users were able to submit proposal or suggestions regarding service design or delivery anonymously. Additionally, if service users preferred to communicate face-to-face, weekly community meetings were scheduled with service manager. However, the impact that these involvement mechanisms had on commissioning was difficult to measure, as despite multiple consultation opportunities existing within a single agency, participants did not explicitly state how the views elicited influenced the final commissioning decision.

Two alcohol agencies, described a less organised approach to service user involvement. Within these two agencies, involvement appeared to take place in a more reactive and unplanned manner, responding to specific needs as they were identified: "It hasn't happened very much other than the anecdotal stuff where a client might come in and say well that so and so is great or that's crap you need to do something about that and then the organisation will respond you know in an anecdotal way a very ad hoc way." (Seth, Service Provider). Although it could be perceived as negative that service user involvement did not happen in a continuous way, it also highlighted the level of flexibility that services have, to be able to instigate change in response to suggestions made regarding their service offer.

\section{User-led innovation}

There were two notable examples where service user participants described their recovery journey and their progression from patient or client to service manager. Within these two examples, individuals whom were current alcohol service managers had drawn upon their own personal treatment journey through alcohol services and had identified potential areas for service redesign. What these rare examples 
illustrate, is that regardless of an individual's status, it is possible to influence commissioners to redesign services if the necessary evidence is collated to identify a gap in service provision: "The services was actually born from a group of individuals in recovery from alcohol and drug addiction and they identified there was a gap in this style of treatment so they met on a voluntary basis over a two year period you know looking at a model in which they could work... so it's actually come from the service level upwards." (Rebecca, Service Provider). In one example, William described a prolonged period of self-funding a potentially commissionable treatment option, in order to demonstrate its need to commissioners: "Service B was registered as a charity in 2005, it started somewhat eighteen months before that as, a support group in my home, and for two and a half years I funded it totally out of my incapacity benefit, yeah, yeah. That's how it started" (William, Service Provider). The two examples above highlight instances where evidence was collated to demonstrate that new elements of service design constituted a legitimate addition to the alcohol treatment pathway.

\section{Discussion}

Analysis of the data from our qualitative case study of alcohol services in the North East of England shows a lack of consistency regarding the opportunities within the commissioning process for stakeholder involvement to occur, with the extent of stakeholder involvement often left to the discretion of individual commissioners $(52,53)$. Using Arnstein's ladder to illustrate the extent of stakeholder involvement, most stakeholders perceived involvement to occur at the level of informing or consultation implying a level of tokenism.

Formal mechanisms were described as occurring at pre-determined time points and were regulated at a national level, leaving little scope for localised nuances to be captured. Data was portrayed as being collated to help construct a national picture of what was happening across service providers, with limited scope for stakeholders to influence design or delivery of services. As described in the findings, service $B$ was an exception to this and it was expressed that service B involved stakeholders in a way that felt genuine, so individuals felt as though their views were heard and actioned. Differences in opinions were present, as commissioners described survey and questionnaires as appropriate mechanisms to obtain service users opinions; whilst the service users themselves portrayed them as the wrong mechanisms, lacking the ability to collect quality and insightful views.

Stakeholders continued to illustrate informal mechanisms of involvement within individual services, these methods were described as responsive and needs led rather than imposed as pre-specified times. The potential for this level of stakeholder involvement to be influential was more prominent at a localised level where there was recognition that service users have 'the answers' and multiple opportunities to become involved were present such as feedback forms, suggestion boxes, evaluation sheets and patient stories. All the mechanisms were available to complete on a continuous basis, providing an open dialogue with the potential for change to occur. 
Stakeholders falling into the professional categories such as service providers and GP's perceived involvement opportunities as a mechanism to monitor their performance and were predominantly depicted as 'consultation'. Professional stakeholders also described a silo-based approach to involvement in decisions, where commissioners worked primarily towards meeting organisational rather than system wide priorities; an issue that persists today $(54,55)$.

Using Arnstein's ladder to contextualise the extent of stakeholder involvement in commissioning (29), the majority of service provider and commissioning stakeholders described involvement that could fluctuate between rung 3 (informing) and rung 5 (placation). Mechanisms of involvement could serve multiple purposes (i.e. contract monitoring, obtaining a national picture, capturing a patient story); subsequently, it was hard to ascertain within each scenario, the level of influence that stakeholder involvement had made (4). Aside from two notable examples, our study found few instances of genuine stakeholder involvement influencing the design and delivery of services. The findings show that commissioners occupied the top rungs of the ladder, and held the position of citizen control, with control of budgets and final decisionmaking. However, it could be argued that the reality of commissioning is that due to continuing austerity, severe financial pressures impact upon every part of the health and social care system (54) resulting in stakeholder involvement not receiving as much time or investment as is necessary and enabling prevailing power structures to remain intact.

Even when stakeholders were given an opportunity to participate in the commissioning process, we found little consensus regarding the actual influence such involvement mechanisms had regarding service design and delivery $(4,35,56-58)$. Indeed this reflects a wider gap in published evidence about what processes and mechanisms are most effective in ensuring stakeholders' voices are heard within commissioning decisions $(56,59-61)$. A study by Rushmer et al (2015) found that members of the public did not have a 'direct voice' regarding the commissioning or implementation of public health interventions to reduce alcohol related harm (52). However, it should also be acknowledged that stakeholder involvement in alcohol services may present additional challenges for the commissioning process, particularly where service users themselves are concerned. For example, our service user participants found it difficult to achieve sufficient distance from their own health challenges to be able to speak on behalf of other service users, both known and unknown, to help shape wider commissioning decisions (4).

Limited literature is available regarding alcohol services, stakeholder involvement and commissioning. However, our data reinforced previous findings in the 2018 CELAD (community engagement in local alcohol decision making) study which found some evidence of community engagement in local alcohol decision making however, there was a lack of clear understanding regarding decision making processes available to stakeholders and a lack of clarity regarding what input counts (62). As with our study, the CELAD study found evidence of involvement at a local level but also concluded that most mechanisms were 'top down' and were managed by local authorities. Our data and previous findings imply a limited level of control regarding how stakeholders are involved in the decision-making process $(63,64)$. 


\section{Strengths And Limitations}

A strength of this study is that it collected data from multiple perspectives and allowed data to be compared and contrasted across participant groups. A further strength is that although the structures undertaking the commissioning (PCT/CCGs) and the processes of commissioning change in name often the underlying functions remain the same, so the issues presented in this paper are as relevant in 2020 as they were when the data collection took place. The issues presented in this paper and the need to develop timely and appropriate mechanism for involvement to occur are significant due to challenges arising due to prolonged austerity and constrained resources for stakeholder involvement to occur (55). Despite a blanket invite to service users regardless of the type of support they accessed (brief intervention, advice and support, therapeutic intervention) the participants whom attended the focus groups were currently accessing or had accessed structured service offering psychosocial interventions, medical detoxes and/or residential rehabilitation). The limited recruitment of service users from the entire spectrum of alcohol treatment provision could mean that the findings are not representative of all stakeholders whom could access alcohol support. Additionally, data collection only took place in the North East of England therefore a common criticism is that it provides a poor representation of the wider population (43). However, whilst recognising this criticism, it should be recognised that generalisation was not the aim of the study, the primary purpose of this paper was to capture the complexity of a situation occurring within and across the case study sites $(4,43)$.

\section{Implications For Policy, Practice And Future Research}

We found that alcohol stakeholders do not perceive themselves as influencing commissioning decisions as fully or consistently as policy proposes that they should (4). Clear guidance of potential opportunities for stakeholder involvement need to be established, and these need to have more dimensionality than stakeholder involvement policies currently afford $(29,65,66)$. Moreover, the mechanisms of involvement need to match the context, such as whether an individual is being involved in developing their own personal care plan, or where individuals contribute to strategic commissioning decisions.

More recently, the choice of terminology has transitioned from 'commissioning' towards an increased focus on planning, collaboration and working across a whole system. Additionally, with the introduction of integrated care systems and devolution being used to support system wide approaches to commissioning, the way commissioning is delivered is continually evolving (67). Arguable, this move to more explicitly promote collaboration should be supportive of improved stakeholder engagement. To achieve meaningful collaborative working, ideally a co-production approach should be taken, in which commissioners, members of the public and professionals work together to share power and responsibility for the commissioning decisions being made. Co-production principles include sharing of power, ensuring all perspectives are represented, respecting and valuing everyone's knowledge, reciprocity, and building and maintaining relationships (68). 
Many participants expressed their disappointment and frustration at the regular use of overly prescriptive methods of stakeholder involvement preferring methods that enabled mechanisms to be innovative and responsive to the environment and context that the involvement was occurring within. Policy documents need to consider developing and/or promoting more appropriate and sustainable mechanisms to involve stakeholders within all stages of the commissioning process. Adopting a co-production approach could enable this to happen.

The introduction of integrated care systems has the potential to boost the concept of stakeholder involvement, however, we do not yet know how successful they could be. Further research using realist evaluation methods to explore how integrated care systems have influenced how care is planned and delivered within complex health care settings such as substance misuse would be useful. Once more evidence is available and has been critically analysed, clear 'best practice' guidance needs to be developed to encourage involvement to become standardised within the commissioning of both alcohol and other public health services.

\section{Conclusion}

All participants interviewed as part of this study were stakeholders. However, for some participant's stakeholder involvement remains rhetorical, the understanding of what stakeholder involvement comprised of, varied among participants, with some definitions implying that involvement only took place at the levels of consultation without successfully reaching levels of partnership or citizen control. Professional participants (including commissioners and alcohol service providers) inferred that stakeholder involvement was often regarded as a means to an end rather than a continuous process, this was highlighted by the heavy reliance on tick box questionnaires; the insinuation being that 'any involvement was good involvement'.

Stakeholder participants identified multiple opportunities for involvement to take place, nevertheless it was hard to establish whether involvement mechanisms influenced planning and decision-making that took place. It is essential within public health that a deeper understanding is generated of who stakeholders are within this complex and fluid environment and to develop a clearer understanding of the different roles that stakeholders can play within the entire commissioning process in order to maximise its utility.

\section{Declarations}

\section{Ethical approval and consent to participate.}

This study was granted a favourable ethical opinion by Sunderland Research Ethics Committee, currently re-named as North East Tyne and Wear South Research Ethics Committee. Newcastle University acted as trial sponsor. The Supervisory team were responsible for ensuring the appropriate and timely implementation of the study. 
Written informed consent was obtained for all participants prior to participation in interviews and/or focus groups.

\section{Consent for publication}

Not applicable

\section{Availability of data and material}

The datasets used and/or analysed during the current study are available from the corresponding author on reasonable request.

\section{Competing interests}

The authors declare that they have no conflict of interests.

\section{Funding}

The PhD was funded by NHS South of Tyne and Wear through the FUSE network. Hayley Alderson is a member of Fuse, the Centre for Translational Research in Public Health (www.fuse.ac.uk). Fuse is a UK Clinical Research Collaboration (UKCRC) Public Health Research Centre of Excellence. Funding for Fuse from the British Heart Foundation, Cancer Research UK, Economic and Social Research Council, Medical Research Council, the National Institute for Health Research, under the auspices of the UKCRC, is gratefully acknowledged. The views expressed in this paper do not necessarily represent those of the funders or UKCRC. The funders had no role in study design, data collection and analysis, decision to publish, or preparation of the manuscript. Grant reference number MR/K02325X/1.

\section{Author's contribution}

All authors have made an intellectual contribution to this research paper. The paper is reporting findings from a PhD study completed by $\mathrm{HA}$. $\mathrm{EK}, \mathrm{DH}, \mathrm{AB}$ and $\mathrm{AO}$ were members of the supervisory team for the PhD. HA wrote the first draft of the paper and all authors have input into drafts and have read and approved the final version of the manuscript.

\section{Acknowledgements}

$\mathrm{HA}, \mathrm{EK}, \mathrm{DH}, \mathrm{AB}$ were responsible for designing the research undertaken as part of a PhD study. HA had responsibility for completing the qualitative research and analysing the data, with support from the 
supervisory team.

We thank all participants for their participation in this study, and for giving their time to participate in interviews.

\section{References}

1. NESTA. People powered commissioning embedding innovation in practices. London: NESTA; 2013.

2. Department of Health. Commissioning framework for health and wellbeing. London: DH; 2007.

3. Department of Health. Commissioning definition (online) 2009 [Available from: http://www.dh.gov.uk/en/Managingyourorganisation/commissioning/index.htm.

4. Alderson H. Exploring commissioners, service providers and treatment service users' views about involvement in public health commissioning:a case study of local alcohol services. Newcastle: Newcastle University; 2016.

5. England N. Framework for patient and public participation in public health commissioning. London: NHS England; 2017.

6. NHS England. Transforming participation in Health and Care. London: NHS England.; 2013.

7. NHS England. Patient and public participation in commissioning health and care: Statutory guidance for clinical commissioning groups and NHS England. London: NHS England; 2017.

8. Department of Health England. Working for Patients. London: Department of Health; 1989.

9. Gibson Aea. Theoretical directions for an emancipatory concept of patient and public involvement. Health Aff. 2012;16(5):531-47.

10. Lewis R, Hinton L. Citizen and staff involvement in health service decision making: Have national health service foundation trusts in England given stakeholders a louder voice? Journal of health service research policy. 2008;13(1):19-25.

11. Department of Health. World Class Commissioning Competencies. London: Department of Health; 2007.

12. Department of Health. World Class Commissioning: Vision Summary. London: DH; $2007 \mathrm{c}$.

13. NHS. The Long Term Plan. London: NHS.; 2019.

14. Miller C. Developing the power of strong, inclusive communities. A framework for Health and Wellbeing Boards. Office for Public Management; 2014.

15. Kickbusch I, Gleicher D. Governance for health in the 21st century.. Copenhagen World Health Organization Regional Office for Europe.; 2012.

16. McMurray R. Our reforms, Our partnerships, Same problems: The chronic case of the English NHS. Public money management. 2007;27:77-82.

17. Stoker G. Public Value management: A new narrative for networked Governance? American review of Public Administration. 2006;36:41-57.

18. Redding D. Engaging with patients. London: National Voices; 2014. 
19. Abelson Jea. Will it make a difference if $\mathrm{i}$ show up and share: A citizens perspective on improving public involvement processes for health system decision making. Journal of health service research policy. 2004;9(4):205.

20. Veronesi G, Keasey K. Policy implementation and stakeholder involvement within the National Health Service. Leeds: Leeds University; 2009.

21. Luoma-atio V, Vos M. Towards a more dynamic stakeholder model: acknowledging multiple issue arenas. Corporate communications: An international Journal. 2010;15(3):315-31.

22. Jeffery N. Stakeholder Engagement: A road map to meaningful engagement. Cranfield University: Doughty Centre; 2009.

23. Elliott E, Williams G. Developing public sociology through health impact assessment. Sociology of Health Illness. 2008;30:1101-16.

24. 13. ed. Glasgow: Harper Collins Publishers; 2018. Collins English dictionary.

25. Cornelissen J. Corporate communication: A guide to theory and practice. 2nd ed. Los Angeles: Sage; 2008.

26. Public Health England. Alcohol and drugs prevention, treatment and recovery: why invest? https://www.gov.uk/government/publications/alcohol-and-drug-prevention-treatment-and-recoverywhy-invest/2018 [.

27. Rehm J, Roerecke M. Reduction of drinking in problem drinkers and all-cause mortality. Alcohol Alcohol. 2013;48:509-13.

28. Plunkett M. User involvement in alcohol services: myth or reality? A literature review.. Scotland; 2008.

29. Arnstein S. A ladder of citizen participation. Journal of the American Institute of planners. 1969;35:216-24.

30. Feingold E. Citizen participation: A review of the issues. cited. In: Rosen HM, Mersch JM, Levey S, editors. The consumer and the health care system: Social and management perspectives. New York: Spectrum; 1977.

31. Burns Dea. The politics of decentralisation. London: Macmillan; 1994.

32. Wilcox D. A to Z of participation. York: Joseph Rowntree Foundation; 1999.

33. Alderson $\mathrm{H}$. Exploring commissioners, service providers and treatment service users' views about involvement in public health commissioning:a case study of local alcohol services. Newcastle: Newcastle University; 2016.

34. LEXICO

LEXICO. Tokenism. https://www.lexico.com/definition/tokenism2019 [.

35. Ocloo J, Matthews R. From tokenism to empowerment: progressing patient and public involvement in healthcare improvement. BMJ Qual safety. 2016;25:626-32.

36. El Enany N, Currie G. A. L. "A Paradox in Healthcare Service Development: Professionalization of Service Users. Soc Sci Med. 2013;80:24-30. 
37. Mossman J, Baker M, Kössler I. Patient Power as a Driver for Change: Reality or Rhetoric? Global policy. 2017;8(52):133-8.

38. Da Silva D. Helping people share decision making. London: The Health Foundation; 2012.

39. Coulter A. Patient Engagement: why is it important. In: Andersson E, Tritter J, Wilson R, editors. Health Democracy: The future of involvment in health and social care. London: NHS National Centre for Involvement; 2006. pp. 27-37.

40. Stevenson Fea. A systematic review of the research on communication between patients and health care professionals about medicines. Health Expect. 2004;7(3):235-45.

41. Vennik F, Van de Bovenkamp H, Putters K, Grit K. Co-production in healthcare: rhetoric and practice. Int Rev Admin Sci. 2016;82(1):150-68.

42. Statistics OfN. Population estimates for the UK, England and Wales, Scotland and Northern Ireland: mid-2017. Hampshire: Office for National Statistics; 2018.

43. Yin R. Case Study Research: Design and Methods. California: Sage; 2009.

44. Gomm R, Hammersley M, Foster P. Case study methods. London: Sage; 2000.

45. Darlington Y, Scott D. Qualitative Research in paractice: Stories from the field. Buckingham: OUP; 2002.

46. Bowling A. Research Methods in Health: Investigating Health and Health Services. 4th ed. Buckingham: Open University Press; 2002.

47. Kvale S, Brinkmann S. Learning the Craft of Qualitative research interviewing. London: Sage; 2009.

48. Patton M. Qualitative evaluation and research methods.. California Sage.; 1990.

49. Fusch P, Ness L. Are we there yet? Data saturation in qualitative research. The Qualitative Report. 2015;20:1208-416.

50. Braun V, Clarke V. Using thematic analysis in psychology. Qualitative research in psychology. 2006;3(2):77-101.

51. Donovan J, Sanders C. Key issues in the analysis of qualitative data in health services research. In: Bowling A, Ebrahim S, editors. Handbook of health research methods: investigation, measurement and analysis. Maidenhead: Open University Press; 2005. pp. 515-32.

52. Rushmer R, Cheetham M, Cox L, Crosland A, Gray J, Hughes L, et al. Research utilisation and knowledge mobilisation in the commissioning and joint planning of public health interventions to reduce alcohol-related harms: a qualitative case design using a cocreation approach. Health Service Deliv Research. 2015;3(33).

53. Hodge S. Participation, discourse and power: a case study in service user involvement. Crit Soc Policy. 2005;25:164-79.

54. LGA. Shifting the centre of gravity: making place-based, person-centred health and care a reality. London: LGA; 2018. Contract No.: 20.11.2019.

55. Wenzel L, Robertson R. What is commissioning and how is it changing?: Kings Fund; 2019 [Available from: https://www.kingsfund.org.uk/publications/what-commissioning-and-how-it-changing. 
56. Mitton C. at al. Public participation in health care priority setting: A scoping review. Health Policy. 2009;91:219-28.

57. Bruni R, Laupacis A, Martin D. Public engagement in setting priorities in health care. Canadian Medical Association Joumal. 2008;179(1):15-8.

58. Mockford C, Staniszewska S, Griffiths F, et al The impact of patient and public involvement on UK NHS health care: a systematic review.. Int J Qual Health Care 2012;24:28-38.

59. Barello S, Graffigna G, Vegni E, Bosio A. 'The Challenges of Conceptualizing Patient Engagement in Health Care: a Lexicographic Literature Review'. Journal of Participatory Medicine. 2014;[online] 6, (e9.).

60. Baggott R, Jones K. 'The Voluntary Sector and Health Policy: the Role of National Level Health Consumer and Patients' Organisations in the UK'. Soc Sci Med. 2014;123:202-9.

61. Fudge $\mathrm{N}$, Wolfe $\mathrm{C}$, McKevitt $\mathrm{C}$. Assessing the promise of user involvment in health service development: ethnographic study. BMJ. 2008;336:313-7.

62. Reynolds J, Egan M. Identifying mechanisms to engagethe community in local alcohol decision making. London: NIHR; 2018.

63. O'Shea A. Whose voices? Patient and public involvement in clinical commissioning. Health Expect. 2016;20:484-94.

64. Pennington A, Watkins M, Bagnall A, South J, Corcoran R. A systematic review of evidence on the impacts of joint decision-making on community wellbeing. London: What Works Centre for Wellbeing; 2018.

65. Wilcox D. Community participation and empowerment: putting theory into practice. York: Joseph Rowntree Foundation; 1994.

66. Feingold E. Citizen participation: A review of the issues. In: Rosen H, Mersch J, Levey S, editors. The consumer and the health care system: social and management perspectives. New York: Spectrum; 1977.

67. Clinical Commissioners. Integrated commissioning for better outcomes. London: LGA and NHS; 2018. Contract No.: 20.11.2019.

68. Ewert B, Evers A. An Ambiguous concept: on the meanings of co-production for health care users and user. organizations? Voluntas. 2014;25:425-42.

\section{Figures}


Arnstein (1969) Ladder of citizen participation

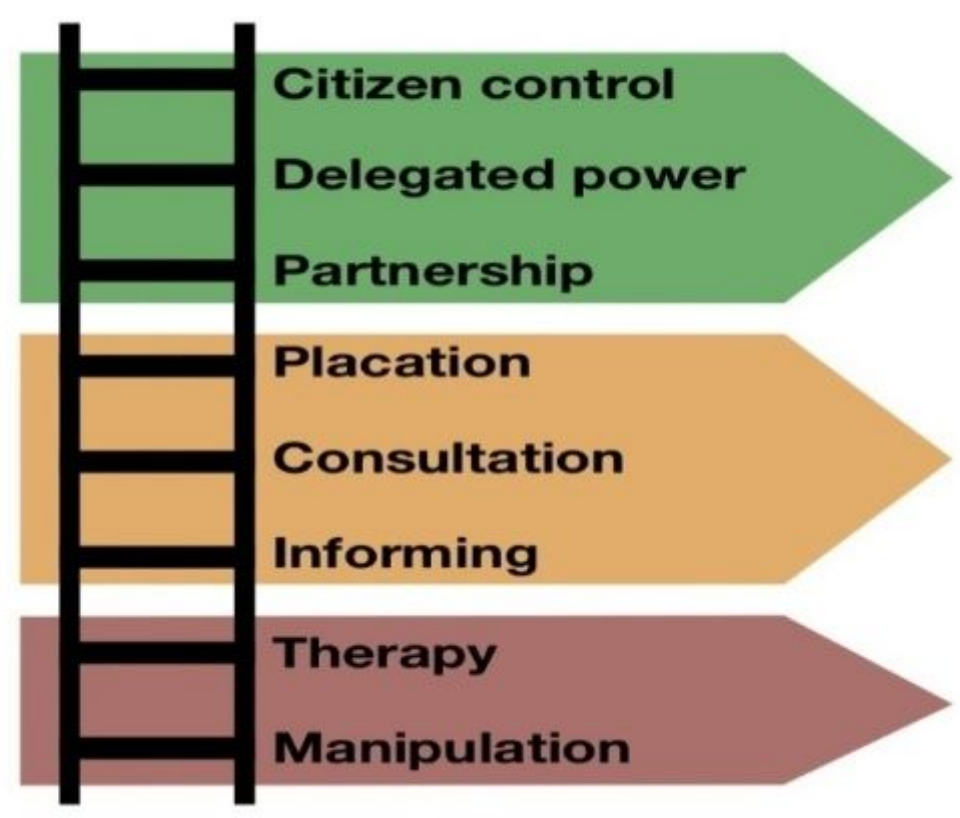

Degrees of citizen power

Degrees of tokenism

\section{No power}

$\$ 3$ George Julian

Figure 1

Arnstein's ladder of participation 